\title{
Signaling pathways involved in liver injury and regeneration in rabbit hemorrhagic disease, an animal model of virally-induced fulminant hepatic failure
}

\author{
Rodrigo García-Lastra ${ }^{1}$, Beatriz SAn-Miguel ${ }^{2}$, Irene CreSPO ${ }^{2}$, \\ Francisco Jorquera ${ }^{2}$, Marcelino Alvarez ${ }^{1}$, Javier GonzÁlez-Gallego ${ }^{2}$, \\ María J. TuÑón ${ }^{2 *}$ \\ ${ }^{1}$ Department of Animal Health, University of León, 24071 León, Spain \\ ${ }^{2}$ Institute of Biomedicine and Centro de Investigación Biomédica en Red de Enfermedades Hepáticas \\ y Digestivas (CIBERehd), University of León, 24071 León, Spain
}

(Received 3 June 2009; accepted 2 September 2009)

\begin{abstract}
Management of fulminant hepatic failure (FHF) continues to be one challenging problem, and experimental animal models resembling its clinical conditions are still needed. Rabbit hemorrhagic disease (RHD) fullfils many requirements of an animal model of FHF. This work investigated changes in MAPK, NF- $\mathrm{BB}, \mathrm{AP}-1$ and STAT pathways during RHD-induced liver injury. Rabbits were infected with $2 \times 10^{4}$ hemagglutination units of an RHD virus isolate. Apoptosis was documented by the presence of caspase-3 activity and substantial PARP proteolysis at 36 and $48 \mathrm{~h}$ postinfection (pi). Infection induced a marked and maintained expression of TNF- $\alpha$ from $12 \mathrm{~h}$ pi, while there was only a transitory increase in IL- 6 expression. Expression of phosphorylated (p)-JNK, p-p38 and p-ERK1/2 was significantly elevated at $12 \mathrm{~h}$ pi. At $48 \mathrm{~h}$ pi p-JNK expression was maintained at a maximum level, while that of p-p38 returned to normality and there was no p-ERK1/2 expression. Activation of NF- $\mathrm{\kappa B}$ and AP-1 and increased expression of VCAM-1 and COX-2 were observed. No significant changes were detected in activation of STAT1 and STAT3, while SOCS3 expression increased significantly. The current findings suggest that activation of JNK is an essential component in liver injury mediated by the RHD virus and that lack of activation of STAT3, probably mediated by SOCS3 over-expression, would contribute to the inhibition of the regenerative response. Data show the presence of molecular mechanisms contributing to liver damage and the lack of regeneration and they support the usefulness of this model to investigate novel therapeutical modalities in FHF.
\end{abstract}

rabbit hemorrhagic disease / fulminant hepatic failure / mitogen-activated protein kinase / nuclear factor kappa B / signal transducer and activator of transcription

\section{INTRODUCTION}

Fulminant hepatic failure (FHF) is a severe liver injury accompanied by hepatic encephalopathy which causes multi-organ failure with an extremely high mortality rate, even if inten-

\footnotetext{
* Corresponding author: mjtung@unileon.es
}

sive care is provided. Management of severe FHF continues to be one of the most challenging problems in clinical medicine [39]. Liver transplantation has been shown to be the more effective therapy, but the procedure is limited by the increasing incidence of liver disease due to immunosuppression requirement and shortage of donor organs [18]. Although

This is an Open Access article distributed under the terms of the Creative Commons Attribution-Noncommercial License (http://creativecommons.org/licenses/by-nc/3.0/), which permits unrestricted use, distribution, and reproduction in any noncommercial medium, provided the original work is properly cited. 
a number of clinical trials testing different liver assisting devices are in progress [42], these systems alone have no significant effect on patient survival and are only regarded as a useful approach to bridge patients with FHF until liver transplantation [48]. As a result, reproducible experimental animal models resembling FHF clinical conditions are still needed to improve our insight into the metabolic and physiological derangements of FHF and to facilitate the development of new therapeutic modalities [3].

At present, the most commonly used surgical and chemical models possess significant limitations and do not accurately reflect the pattern of human disease in FHF. Moreover, viral hepatitis remains an important cause of FHF in many parts of the world, but the use of infective agents to induce experimental FHF have so far had very limited success [3]. Rabbit hemorrhagic disease virus (RHDV) is a member of the Caliciviridae family that causes in wild and domestic rabbits an acute highly fatal disease that was first reported over two decades ago [19]. The disease is characterized by severe necrotizing hepatitis and disseminated intravascular coagulation, neurologic symptoms and rapid evolution to death within 48 to $72 \mathrm{~h}$ after infection in about $90 \%$ of the cases [1]. Hepatic damage plays a central pathogenic role and is histologically similar to fatal viral hepatitis causing FHF in humans [24]. We have shown by data on animal survival, clinical features, histological data, changes in blood chemistry and intracranial pressure monitoring that RHD fulfils many of the requirements of an animal model for FHF [46, 47]. We have also reported that in this model there is a loss in the oxidant/ antioxidant balance [35], and that apoptosis, induced via both the intrinsic and the extrinsic signaling pathways, is a constant feature in experimentally infected rabbits [36]. This model could therefore be useful to improve our insight into the pathophysiology of viral FHF and to facilitate the development and evaluation of new therapeutic modalities.

Viral infection causes the deregulation of various host cellular pathways, some of which reflect cellular response to infection, while others are the result of viral modifications of cellular environments [14]. A common strategy that a virus uses to facilitate its infection and replication is to exploit those altered cellular pathways, which can also contribute to the pathogenesis induced by viral infections [29]. Although the exact significance still remains unknown, recent reports have shown that several viruses, such as human immunodeficiency virus type 1 , human cytomegalovirus, hepatitis B virus, herpes simplex virus type 1 , and others can induce the activation of MAPK pathways in infected cells [53]. Modulation of the redox-sensitive transcription factors NF- $\mathrm{KB}$ and $\mathrm{AP}-1$ have also been reported following infection by the Epstein-Barr virus, influenza virus or Kaposi's sarcoma-associated herpes virus [28] while the role of STAT in antiviral responses and pathways regulating apoptosis is well-known [5]. The aim of the present study was to examine changes in MAPK, NF- $\mathrm{B}, \mathrm{AP}-1$ and STAT pathways during RHDV-induced liver cell injury.

\section{MATERIALS AND METHODS}

\subsection{Virus and experimental model}

Nine-week-old male New Zealand white rabbits were kept in a climatized room at $21{ }^{\circ} \mathrm{C}$, with a $12 \mathrm{~h}$ light cycle. They were given a standard dry rabbit food and water ad libitum. Rabbits were injected intramuscularly with $2 \times 10^{4}$ hemagglutination units of an RHDV isolate [35, 46]. We have previously reported that during experimental RHDV infection, biochemical data (ALT, AST, bilirubin, coagulation factor or Fisher index) change remarkably at 36$48 \mathrm{~h}$ postinfection (pi), with a $10-15 \%$ survival rate by $48 \mathrm{~h}$ pi [46]. We thus decided to study the effects of infection on the hepatocyte signaling pathway by sacrificing a group of control rabbits $(n=6)$ and batches of infected animals at 12, 24, 36 and $48 \mathrm{~h}$ pi $(n=6$ each) [36]. The research was carried out in accordance with the Declaration of Helsinki (2000) of the World Medical Association. All study protocols were reviewed and approved by the University of Leon Animal Care Committee.

\subsection{Blood chemistry}

Laboratory determinations included ALT, AST, and bilirubin. Analyses were carried out in the Hospital of Leon Clinical Chemistry Laboratory using standard techniques. 


\subsection{Caspase-3 activity}

Lysates were prepared by homogenizing liver tissue in $0.25 \mathrm{mM}$ sucrose, $1 \mathrm{mM}$ EDTA, $10 \mathrm{mM}$ Tris and a protease inhibitor cocktail (Roche Diagnostics $\mathrm{GmbH}$, Mannheim, Germany). The lysates were then centrifuged at $14000 \times g$ for $10 \mathrm{~min}$ at $4{ }^{\circ} \mathrm{C}$, and supernatants $(50 \mu \mathrm{g}$ protein) were incubated for $1 \mathrm{~h}$ at $37{ }^{\circ} \mathrm{C}$ in HEPES buffer containing $100 \mu \mathrm{M}$ concentrations of the specific fluorogenic substrate AcDEVD-AMC. Cleavage of the caspase-3 substrate was monitored at excitation wavelength of $360 \mathrm{~nm}$ and emission wavelength of $460 \mathrm{~nm}$, respectively using a spectrofluorimeter (Hitachi F-2000 fluorimeter, Hitachi Ltd., Tokyo, Japan) [36]. Activity was expressed as fluorescence units per milligram of protein per min of incubation. Protein content of samples was quantified with the Bradford assay.

\subsection{Nuclear extract isolation}

Nuclear extracts were prepared from liver homogenates as described previously [21]. Briefly, $100 \mathrm{mg}$ of liver from control and RHDV-infected rabbits were homogenized in $5 \times 10^{-4} \mathrm{~L}$ of buffer A $(0.01 \mathrm{M}$ Hepes-KOH pH 7.9; $250 \mathrm{~g} / \mathrm{L}$ glycerol, $0.420 \mathrm{M}$ $\mathrm{NaCl}, \quad 0.0015 \mathrm{M} \quad \mathrm{MgCl}_{2}, 2 \times 10^{-4} \mathrm{M}$ EDTA, $5 \times 10^{-4}$ M DTT, $2 \times 10^{-4}$ M PMSF) and a phosphatase inhibitor cocktail (Roche Diagnostics $\mathrm{GmbH}$, Mannheim, Germany) to disrupt extracellular matrix and cellular membranes. Homogenates were centrifuged at $1000 \times g$ for $10 \mathrm{~min}$ at $4{ }^{\circ} \mathrm{C}$. The pellet was resuspended in $2.5 \times 10^{-4} \mathrm{~L}$ of buffer $\mathrm{B}$ (0.02 M NaCl Hepes-KOH pH 7.9, $250 \mathrm{~g} / \mathrm{L}$ glycerol, $0.42 \mathrm{M} \mathrm{NaCl}, 15 \times 10^{-4} \mathrm{M} \mathrm{MgCl}_{2}, 2 \times 10^{-4} \mathrm{M}$ EDTA, $5 \times 10^{-4} \mathrm{M}$ DTT, $2 \times 10^{-4} \mathrm{M}$ PMSF), homogenized and incubated at $4{ }^{\circ} \mathrm{C}$ for $30 \mathrm{~min}$. Cellular debris was removed by centrifugation at $14000 \times g$ for 15 min at $4{ }^{\circ} \mathrm{C}$. The supernatant fraction containing DNA binding proteins was recollected and stored at $-80{ }^{\circ} \mathrm{C}$ in aliquots until use.

\subsection{Western blot analysis}

For Western blot analysis of TNF- $\alpha$, IL-6, ERK1/ 2, phospho-ERK1/2, p38, phospho-p38, JNK, phospho-JNK, STAT1 and STAT3, liver tissue was homogenized in $10 \mathrm{mM}$ Tris buffer $(\mathrm{pH}$ 7.4) containing $100 \mathrm{mM} \mathrm{NaCl}$ and protease and phosphatase inhibitor cocktails (Roche Diagnostics $\mathrm{GmbH}$, Mannheim, Germany) and centrifuged at $13000 \times g$ for $30 \mathrm{~min}$ [17]. Cleavage products of
PARP, p50, p65, phospho-STAT1 and phosphoSTAT3 were measured in nuclear extracts. Protein concentration of the cytosolic and nuclear liver fractions was measured by the Bradford assay. Equal amounts of protein $(25-50 \mu \mathrm{g})$ were separated by $10-12 \%$ sodium dodecyl sulphate-polyacrylamide gel electrophoresis and transferred electrically to polyvinyllidene difluoride membranes (Millipore, Bedford, MA, USA). The membranes were then blocked with $5 \%$ non-fat dry milk in Tris-buffered saline containing $0.05 \%$ Tween 20 (TBST) for $30 \mathrm{~min}$ at $37{ }^{\circ} \mathrm{C}$ and probed overnight at $4{ }^{\circ} \mathrm{C}$ with polyclonal anti-TNF- $\alpha$, IL-6, SOCS3, COX-2 (1:1000 Abcam, Cambridge, UK), ERK1/2, phospho-ERK1/2, p65, p50, VCAM-1, PARP (1:200 Santa Cruz Biotechnology, Santa Cruz, CA, USA), p38, phospho-p38, JNK1, phospho-JNK1, STAT1, phospho-STAT1, STAT3 and phospho-STAT3 (1:1000 Cell Signaling Technology, Danvers, MA, USA). Equal loading of protein was demonstrated by probing the membranes with a rabbit anti- $\beta$-actin polyclonal antibody (Sigma, St. Louis, MO, USA; 1:1000). After washing with TBST, the membranes were incubated for $1 \mathrm{~h}$ at room temperature in TBST containing secondary antibody (Dako, Glostrup, Denmark; 1:4000). The membranes were briefly incubated with ECL detection reagent (ECL; Amersham, Buckinghamshire, UK) to visualize the proteins and then were exposed in a cassette for 5 min to an X-ray film (Hyperfilm ECL; Amersham Pharmacia, Uppsala, Sweden) [11, 22]. The film was then developed in $16 \%$ Ilford Phenisol developer solution and fixed in 16\% Ilford Hypam rapid fixer solution (Ilford Imaging UK Ltd., Cheshire, England, UK). Membranes were scanned with a CCD camera and quantified using a Scion Image Software (version 4.0.3.2, Scion Corporation, Frederick, MD, USA). The protein expression rates were normalized through the corresponding expression rates of $\beta$-actin.

\subsection{Electrophoretic mobility shift assay (EMSA)}

Activation of transcription factor NF- $\mathrm{\kappa B}$ and AP-1 was examined using consensus oligonucleotides of NF- $\kappa \mathrm{B}\left(5^{\prime}\right.$-AGT TGA GGG GAC TTT CCC AGG C-3') and AP-1 (5'-CGC TTG ATG AGT CAG CCG GAA-3') $[6,25]$. Probes were labeled by T4 polynucleotide kinase. Binding reactions included $10 \mu \mathrm{g}$ of nuclear protein in incubation buffer (50 mM Tris- $\mathrm{HCl} \mathrm{pH} 7.5,200 \mathrm{mM} \mathrm{NaCl}, 5 \mathrm{mM}$ EDTA, $5 \mathrm{mM}$ mercaptoethanol, $20 \%$ glycerol and $1 \mu \mathrm{g}$ poly(dI-dC)). After $15 \mathrm{~min}$ on ice, the labeled oligonucleotide $(30000 \mathrm{cpm})$ was added and the mixture was incubated $20 \mathrm{~min}$ at room temperature. 
Table I. Blood biochemical changes in infected rabbits.

\begin{tabular}{lccccc}
\hline & Control & $12 \mathrm{~h} \mathrm{pi}$ & $24 \mathrm{~h} \mathrm{pi}$ & $36 \mathrm{~h} \mathrm{pi}$ & $48 \mathrm{~h} \mathrm{pi}$ \\
\hline ALT (IU/L) & $79 \pm 8$ & $73 \pm 9$ & $72 \pm 14$ & $687 \pm 207^{*}$ & $1668 \pm 149^{*}$ \\
AST (IU/L) & $25 \pm 4$ & $23 \pm 3$ & $50 \pm 20^{*}$ & $1010 \pm 372^{*}$ & $3585 \pm 1923^{*}$ \\
Bilirubin (mg/dL) & $0.46 \pm 0.12$ & $0.45 \pm 0.34$ & $0.98 \pm 0.37^{*}$ & $1.29 \pm 0.34^{*}$ & $2.03 \pm 0.43^{*}$ \\
\hline
\end{tabular}

Data represent the mean \pm S.D. from 6 rabbits in each group.

${ }^{*} p<0.05$ Significantly different from control animals.

For competition studies, $3.5 \mathrm{pmol}$ of unlabeled NF$\mathrm{\kappa B}$ oligonucleotide (competitor) or $3.5 \mathrm{pmol}$ of labeled NF- $\kappa \mathrm{B}$ oligonucleotide mutate (non-competitor) were mixed $15 \mathrm{~min}$ before the incubation with the labeled oligonucleotide. The mixture was electrophoresed through a $6 \%$ polyacrylamide gel for $90 \mathrm{~min}$ at $220 \mathrm{~V}$. The gel was then dried and autoradiographed at $-70{ }^{\circ} \mathrm{C}$ overnight. Signals were densitometrically analyzed in an imaging densitometer (Scion Image).

\subsection{Statistical analysis}

Means and S.D. were calculated for all data. Significant differences between means were evaluated by analysis of variance and in the case of significance a Dunnett test was also applied. A difference was considered significant when $p$ was less than 0.05 . Calculations were performed with SPSS+ vrs. 14.0 statistical software (Chicago, IL, USA).

\section{RESULTS}

\subsection{Blood chemistry changes in RHDV-infected animals}

In rabbits experimentally infected with $2 \times 10^{4}$ hemagglutination units of an RHDV isolate, plasma AST activity and bilirubin concentration increased significantly from $24 \mathrm{~h} \mathrm{pi}$, and ALT activity from $36 \mathrm{~h}$ pi when compared to control animals $(p<0.05)$. Values reached a maximum at $48 \mathrm{~h}$ pi $(p<0.05)$ (Tab. I).

\subsection{RHDV-infected animals showed higher rates of apoptosis}

To determine the presence of apoptosis in RHDV-infected animals, the activity of caspase-3 was studied using the specific substrate Ac-DEVD-AMC. Infection resulted in a marked increase of caspase- 3 activity at $36 \mathrm{~h}$
(12.5 fold of control) and $48 \mathrm{~h}$ pi (12.6 fold) $(p<0.05)$ (Fig. 1). Caspase-3 is primarily responsible for the cleavage of PARP, a nuclear enzyme that is catalytically activated by DNA strand interruptions. As expected, substantial PARP proteolysis was documented by the appearance of a characteristic $85-\mathrm{kDa}$ fragment at $36 \mathrm{~h}$ (2.9 fold) and $48 \mathrm{~h}$ pi (3.7 fold) $(p<0.05)$ (Fig. 1).

\subsection{RHDV-infected animals exhibited increased cytokine and MAPK expression}

An increase in TNF- $\alpha$ expression occurred early within $12 \mathrm{~h}$ pi (14.3 fold) and the values remained markedly elevated until $48 \mathrm{~h}$ pi (20.0 fold) $(p<0.05)$. Expression of IL-6 was not modified until $24 \mathrm{~h}$ pi (1.8 fold) $(p<0.05)$ and showed a much smaller increase, returning to normal values by $36 \mathrm{~h}$ pi (Fig. 2).

To confirm that MAPK activation occurred in the liver of RHDV-infected rabbits, we examined phosphorylation of ERK1/2, p38 and JNK by Western blot analysis. Densitometric analysis revealed that the relative level of $\mathrm{p}$ ERK1/2, p-p38 and p-JNK1 normalized to that of $\beta$-actin was significantly enhanced beginning at $12 \mathrm{~h}$ after RHDV infection $(3.1,1.2$ and 2.1 fold, respectively). At $48 \mathrm{~h}$ pi, p-JNK expression was maintained at a maximal level (3.5 fold) while that of p-p38 returned to normal levels and no expression of $p$-ERK $1 / 2$ was detected (Fig. 3).

\subsection{NF- $\mathrm{NB}$ and AP-1 were activated in RHDV- infected animals}

To confirm if activation of MAPK following RHDV infection was associated to the activation 


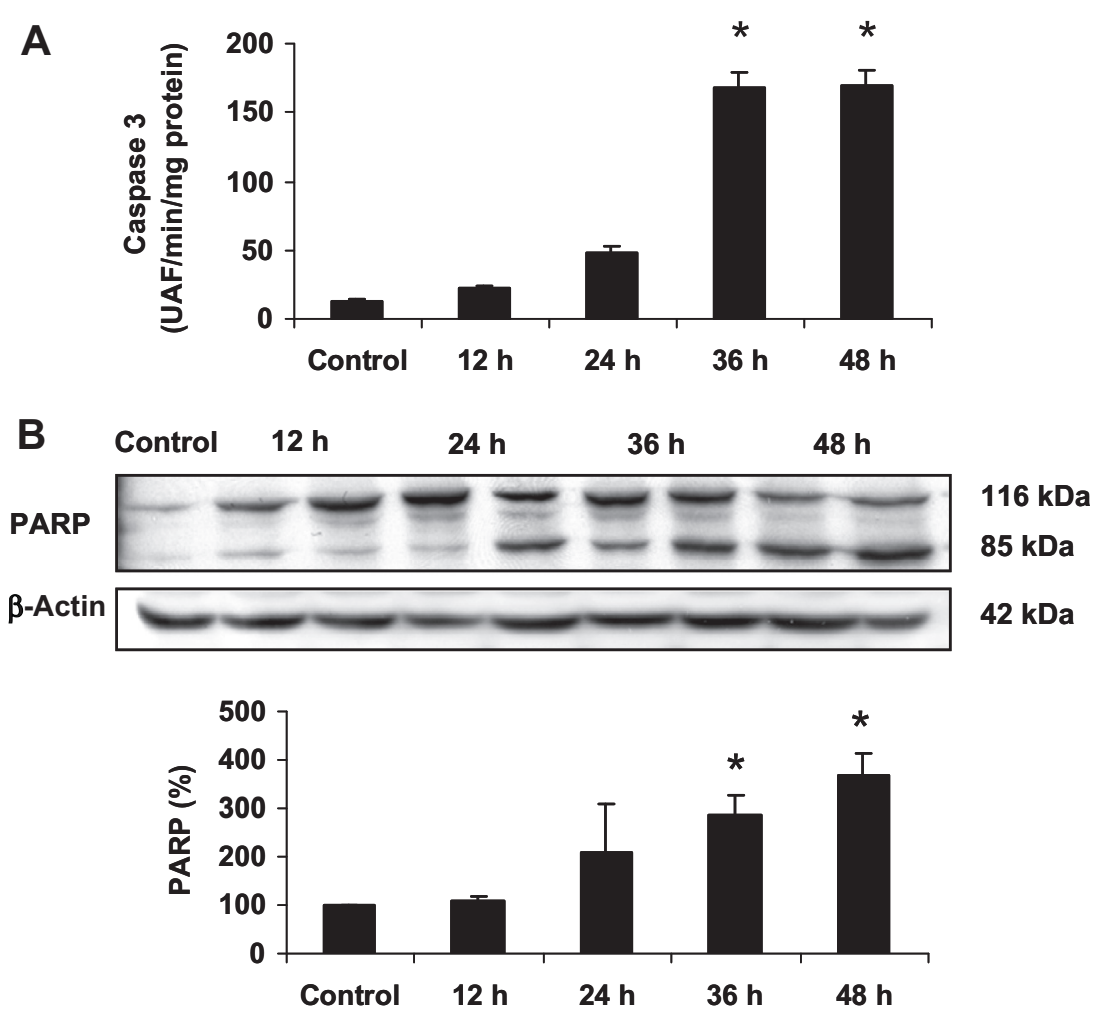

Figure 1. Effect of RHDV infection on liver caspase-3 activity and expression of PARP. (A) Caspase-3 activity. (B) Western blot analysis for PARP. Upper panel: representative Western blots. Lower panel: densitometric analysis. Values are means \pm S.D. from 6 animals. ${ }^{*} p<0.05$ significantly different from control animals.

of NF- $\mathrm{KB}$ and AP-1 pathways, nuclear translocation of both transcription factors was evaluated by EMSA performed with NF- $\mathrm{KB}$ or AP-1 consensus nucleotide sequences. As shown in Figure 4, gel shift experiments indicated that RHDV infection induced a significant activation of NF- $\mathrm{\kappa B}$ at $36 \mathrm{~h}$ (1.9 fold) and $48 \mathrm{~h}$ pi (2.5 fold) $(p<0.05)$. Activation of AP-1 was observed as early as $12 \mathrm{~h}$ pi and increased progressively, reaching a maximum at $36 \mathrm{~h}$ pi (1.8 fold). Western blot analysis of $\mathrm{p} 50$ and $\mathrm{p} 65 \mathrm{NF}-\mathrm{\kappa B}$ subunits (Fig. 5) confirmed the increased translocation of this transcription factor to the cell nucleus.

Expression of the downstream targets of various transcription factors VCAM-1 and COX-2 was also examined by Western blot. Densitometric analysis indicated that expression increased significantly from $12 \mathrm{~h}$ pi (1.3 fold and 2.7 fold for VCAM-1 and COX-2 respectively) and remained significantly elevated until 48 h pi $(p<0.05)$ (Fig. 6).

\subsection{STAT and SOCS3 expression in RHDV- infected animals}

STAT are transcription factors with antiviral properties which are involved in the regenerative process during FHF. The expressions of total and phosphorylated STAT1 and STAT3 were tested by Western blot analysis in liver nuclear extracts. RHDV infection did not result in nuclear STAT3 expression, while a transitory increase in STAT1 (with no significant mean change) was occasionally observed at $24 \mathrm{~h}$ 

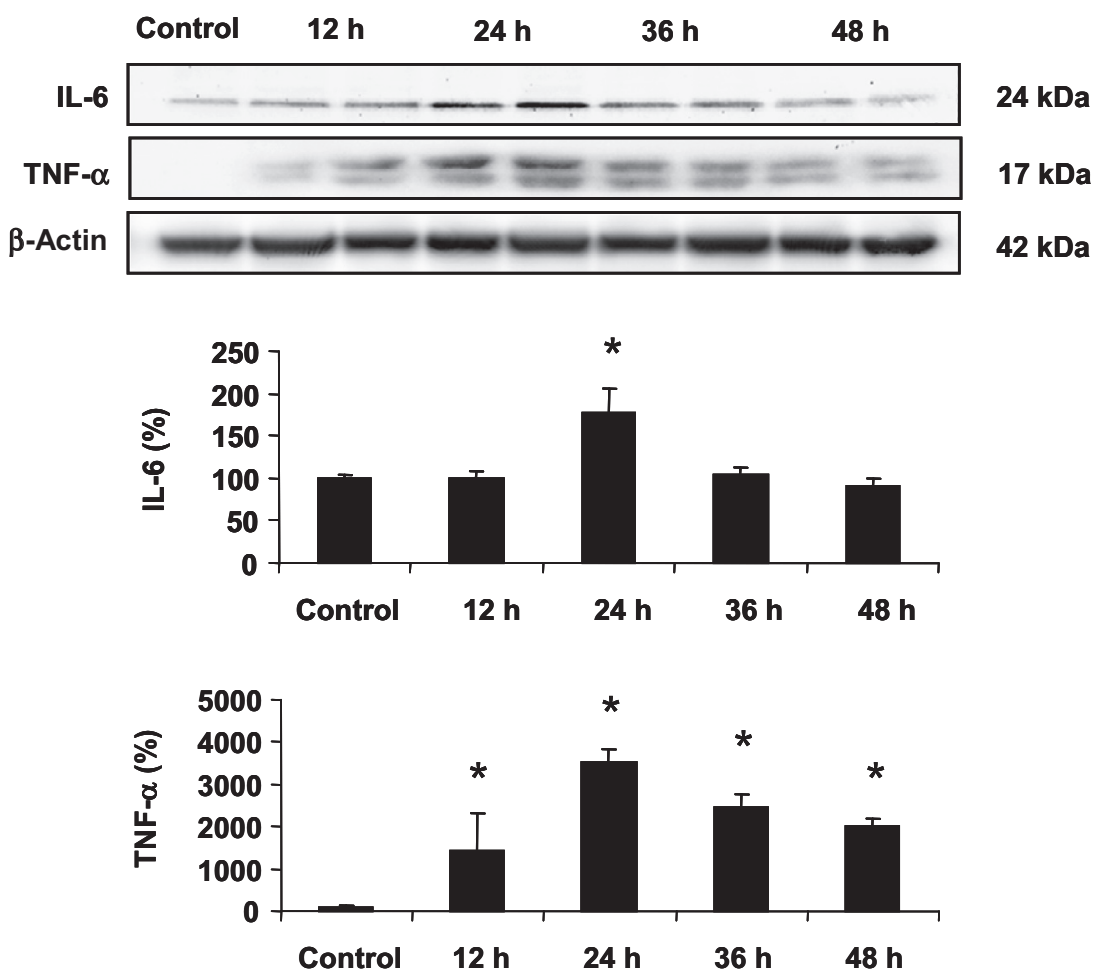

Figure 2. Effect of RHDV infection on liver expression of TNF- $\alpha$ and IL-6. Upper panel: representative Western blots. Lower panel: densitometric analysis. Values are means \pm S.D. from 6 animals. ${ }^{*} p<0.05$ significantly different from control animals.

and $36 \mathrm{~h}$ pi in some animals. Expression of the endogenous inhibitor of STAT signaling SOCS3 increased from $24 \mathrm{~h}$ pi (1.3 fold) and remained significantly elevated at $36-48 \mathrm{~h}$ pi (1.7 fold) $(p<0.05)$ (Fig. 7).

\section{DISCUSSION}

Inflammatory processes are the main cause for the initiation of the host defense mechanisms against disturbances of its physiological homeostasis. The mediators responsible for the acute phase response are predominantly cytokines, including TNF- $\alpha$, a pro-inflammatory cytokine and a mediator of the acute phase response that has been reported to be increased in the serum of FHF patients [26]. In the liver of mice and patients with FHF, liver cells express high amounts of TNF- $\alpha$ and TNF receptor (TNF-R), and a direct correlation has been demonstrated with the number of apoptotic hepatocytes and the risk of death [40]. Moreover, TNF- $\alpha$ induces massive apoptosis of hepatocytes in mice with GalN/LPS-induced FHF $[27,33]$. Thus, for TNF- $\alpha$, over-expression could be an important contributor to the induction of apoptosis by the RHDV infection. On the contrary, processes dependent on IL-6, a downstream hepatotrophic effector cytokine induced by TNF- $\alpha$, are mainly conferred to be protective, and it is known that liver regeneration is enhanced by a designer IL-6/soluble IL-6 receptor fusion protein with superagonistic IL-6 properties [9]. In our study, although IL-6 expression increased at $24 \mathrm{~h} \mathrm{pi}$, it returned to normal by 36 and $48 \mathrm{~h}$ pi, periods in which there was a marked activation of apoptosis. 

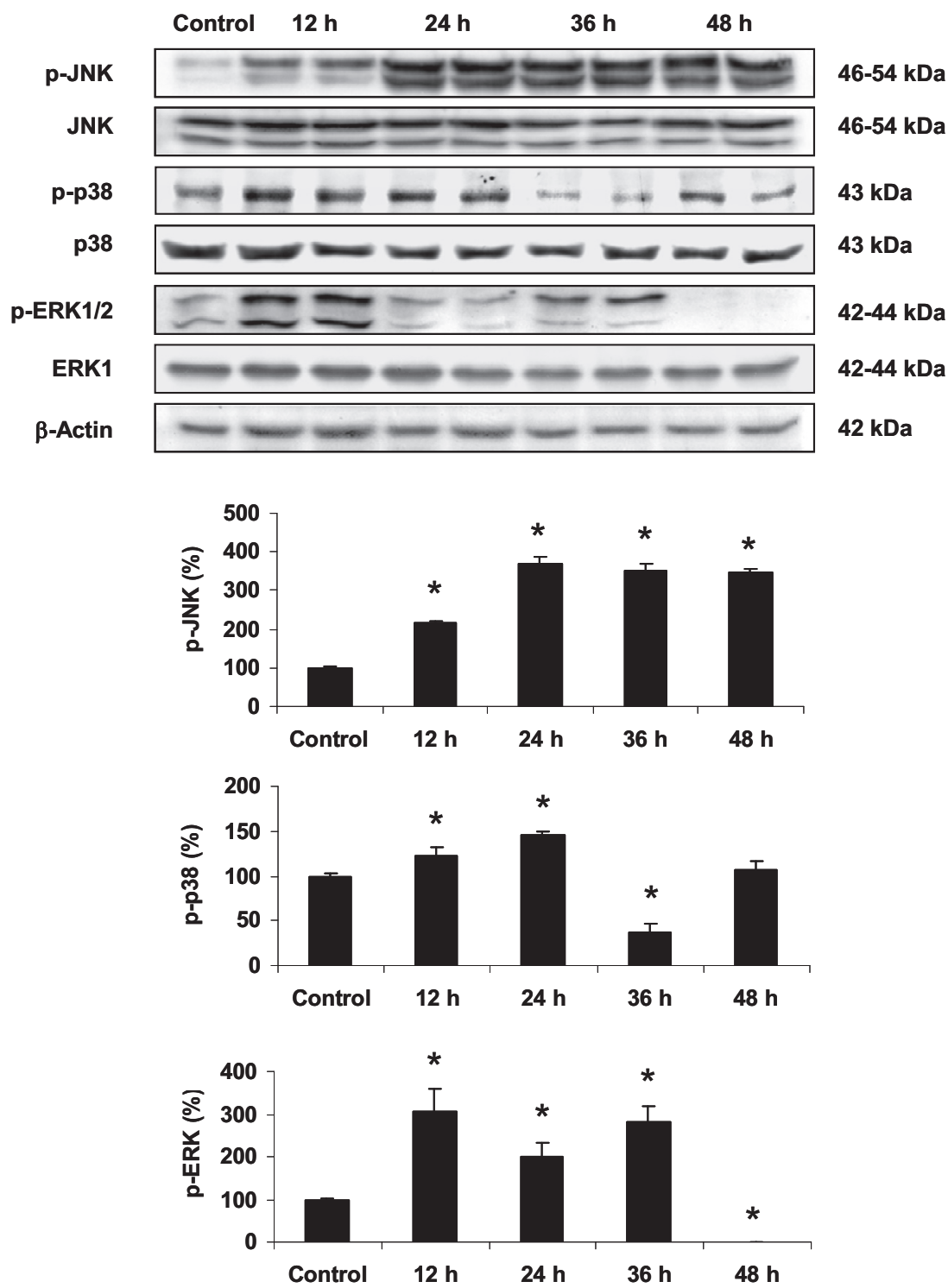

Figure 3. Effect of RHDV infection on liver expression of phosphorylated and total JNK, p38 and ERK1/2. Upper panel: representative Western blots. Lower panel: densitometric analysis. Values are means \pm S.D. from 6 animals. ${ }^{*} p<0.05$ significantly different from control animals.

MAPK are a family of serine/threonine kinases with three major types in mammalian cells, ERK1/2, p38 and JNK, which represent a group of proteins involved in the signal transduction of a variety of cellular stimuli [41].
ERK1/2 differs from the two other major MAPK members by the lack of strong linkage with induction of pro-inflammatory responses but, rather, is thought to play a role regulating proliferation, transformation and differentiation 

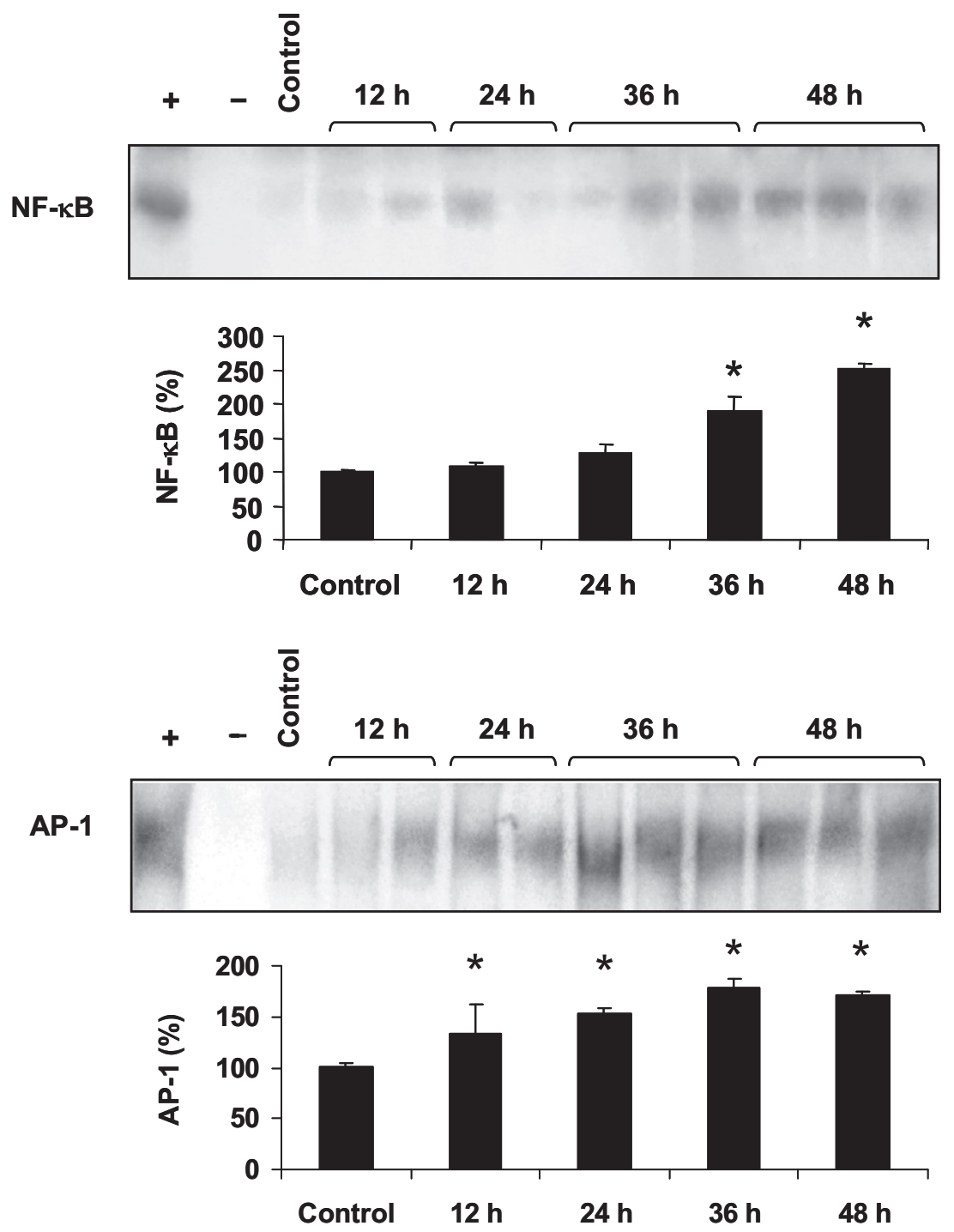

Figure 4. Effect of RHDV infection on nuclear factor $N F-\kappa B$ and $A P-1$ activation. Upper panel: representative EMSA for NF- $\kappa B$ and AP-1. Specific binding was verified by addition of unlabeled oligonucleotide (competitor, -) or labeled oligonucleotide mutate (non-competitor, + ). Lower panel: densitometric analysis. Values are means \pm S.D. from 6 animals. ${ }^{*} p<0.05$ significantly different from control animals.

[16]. Moreover, in many cell types, whereas ERK1/2 generally inhibits apoptotic processes, JNK and $\mathrm{p} 38$ MAPK contribute to the induction of apoptosis [49]. JNK activation is known to trigger apoptosis in response to environmen- tal stress as well as inflammatory cytokines such as TNF- $\alpha$ [13].

In RHDV-infected animals, p38 expression increased at early periods but had normalized by $24 \mathrm{~h} \mathrm{pi}$, while there was a sustained 


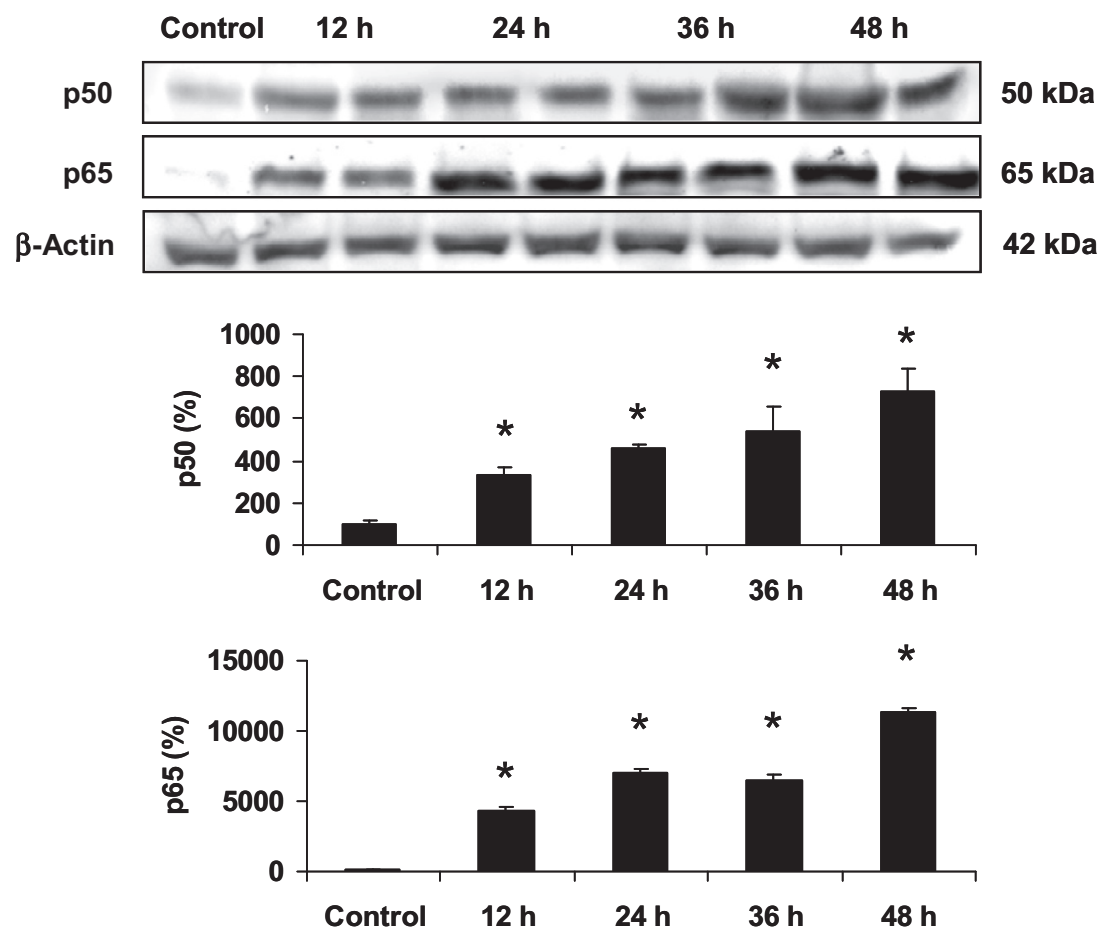

Figure 5. Effect of RHDV infection on the liver expression of p50 and p65. Upper panel: representative Western blots. Lower panel: densitometric analysis. Values are means \pm S.D. from 6 animals. ${ }^{*} p<0.05$ significantly different from control animals.

up-regulation of JNK. In hepatocyte apoptosis induced by concanavalin $\mathrm{A}$, a methionineand choline-deficient diet, or D-galactosamine/ lipopolysaccharide, JNK has been shown to play a critical role [37]. JNK activity is required for the mitochondrial damage-mediated activation of cell death effectors, including caspase9 and caspase- 3 , and it modulates some Bcl-2 family proteins on multiple levels [43]. It is also known that transient JNK activation leads to cell proliferation and is required for liver regeneration [38], whereas sustained JNK promotes cell death [20]. In our animal model apoptotic damage was associated to a maintained JNK activation, which thus appeared to play a key role in the cell response to infection.

Although it should be emphasized that signal transduction mechanisms are generally cross-regulated in an intricate network [2], both p38 and JNK phosphorylation have been related to NF- $\mathrm{NB}$ and $\mathrm{AP}-1$ activation partly by converging pathways [8]. The activation of JNK is essential for the up-regulation of AP-1-dependent genes induced by viruses in various cell types. It is also known that viral infection may induce NF- $\kappa \mathrm{B}$ transcriptional activity through activation of $\mathrm{JNK}$ and p38 [45]. Activation of MAPK could thus contribute to the increased nuclear translocation of both transcription factors to the nucleus. $\mathrm{NF}-\kappa \mathrm{B}$ is a hallmark of most infections by viral pathogens, mediating expression of many proinflammatory or antiviral genes, and has been involved in adhesion molecule gene expression at the transcriptional level [45]. AP-1 is also activated during infection and regulates the expression of a large variety of genes including those involved in the inflammatory response [4]. In our study, the expression of the adhesion molecule VCAM-1 and the enzyme COX-2, 


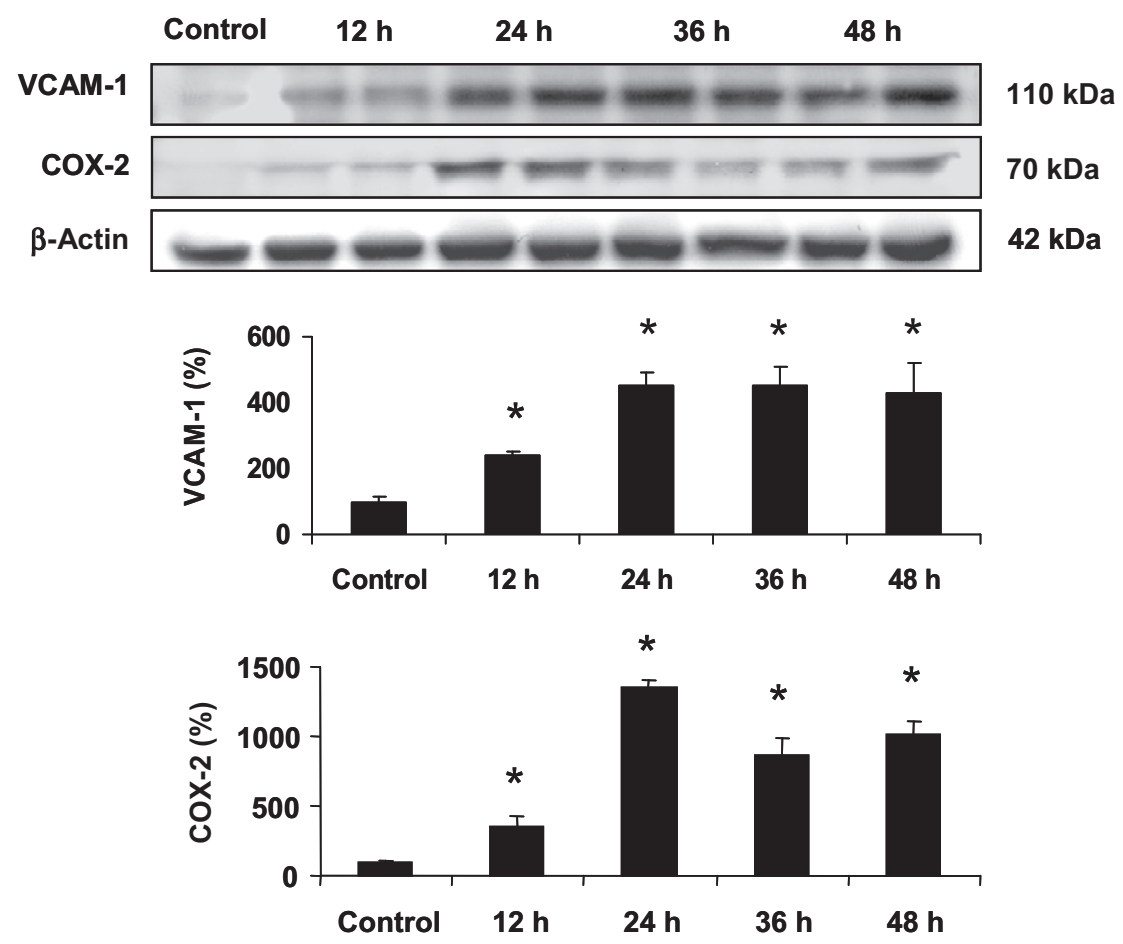

Figure 6. Effect of RHDV infection on the liver expression of VCAM-1 and COX-2. Upper panel: representative Western blots. Lower panel: densitometric analysis. Values are means \pm S.D. from 6 animals. $* p<0.05$ significantly different from control animals.

both contributing to liver injury in FHF [12, 51], were up-regulated in RHDV-infected rabbits. The effects on these downstream targets could be accounted for, at least partially, by the activation of NF- $\kappa \mathrm{B}$ and/or AP-1.

In FHF, the regenerative response is essential for the full functional recovery of the liver and for patient survival, and the expression of genes does not lead to DNA replication unless the cells can progress through the cell cycle. This is dependent on the balance between stimulatory factors released as part of the regenerative response and inhibitory substances [34]. Members of the STAT family have been reported to be involved in regeneration and to play a key role in antiviral defense. Thus, STAT1, when phosphorylated, forms heterodimers, which then translocate into the nucleus to activate the transcription of many target genes, including several antiviral proteins [32]. The essential role of STAT1 in the antiviral and antitumor activity of INF- $\alpha / \beta$ has been clearly demonstrated in STAT1-deficient mice [23]. It is known that STAT1 is activated in several models of acute liver injury, including Concanavalin A-induced hepatitis and LPS/D-galactosamineinduced liver damage [15]. In the liver, STAT3, mainly activated by IL-6, has been shown to play key roles in acute phase response, protection against liver injury and promotion of liver regeneration [10]. Lethality following partial hepatectomy in TNF-R1 knock out mice is reversed by administration of IL-6 and associated activation of STAT3 [52]. Several STAT3 downstream genes have been identified as important factors contributing to the hepatoprotective and hepatomitogenic effect of IL-6/ STAT3 [44]. Activation of STAT3 has also been implicated in INF- $\alpha$-mediated antiviral activity in hepatitis $\mathrm{C}$ virus replicon cell line [54]. Data 

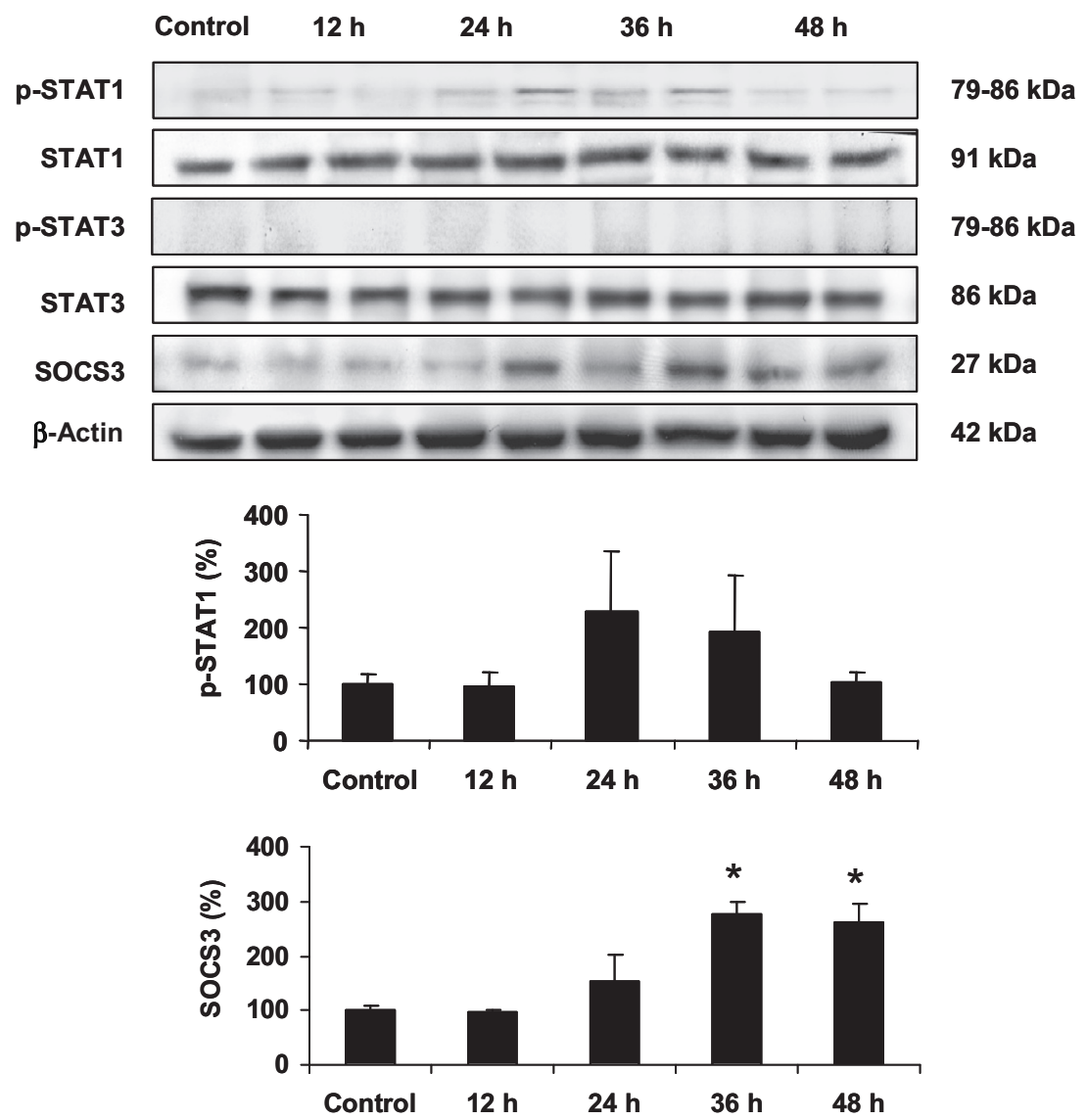

Figure 7. Effect of RHDV infection on liver expression of STAT1, STAT3 and SOCS3. Upper panel: representative Western blots. Lower panel: densitometric analysis. Values are means \pm S.D. from 6 animals. ${ }^{*} p<0.05$ significantly different from control animals.

from the present research indicate that a transitory STAT1 activation was occasionally observed, but STAT3 was not significantly activated in RHVD-infected rabbits, an effect which could contribute to the lack of regenerative response detected in those animals [35].

Blocking the function of STAT proteins has evolved as a common mechanism for pathogen immune evasion, and numerous viruses, including hepatitis $\mathrm{C}$ virus, paramixoviruses or coronaviruses have developed mechanisms to circumvent the host defense by inhibiting host signalling and by disrupting the cross-talk between the MAPK and STAT pathways [7].
One of these mechanisms involves a suppressor of cytokine signaling (SOCS) proteins. It is known that virus titres are reduced in SOCS3 deficient cells or in cells where SOCS3 expression is knocked-down by siRNA [30]. Moreover, it has been reported that the level of induction of SOCS3 by HSV-1 seems to determine whether infection turns to acute or persistent progression. In addition, it has been suggested that SOCS3 up-regulation may contribute to the non-responsiveness of $\mathrm{HCV}$ patients to IFN therapy [31]. The effects mediated by SOCS are related to the fact that these molecules are potent endogenous inhibitors of 
STAT signaling. Thus, it has been reported that targeted deletion of SCOS3 in macrophages results in markedly enhanced IL-6-induced STAT3 activation, and that over-expression of SOCS3 in human hepatoma HepG2 cells suppresses IFN- $\alpha$-induced STAT $1 / 3$ activation and gene expression of the antiviral proteins [50]. Although other mechanisms could be involved, the fact that SOCS3 was overexpressed in infected rabbits most probably contributed to the inhibition of STAT $1 / 3$ expression and therapeutic strategies to block SOCS could be of interest to prevent liver damage and to increase survival in FHF of viral origin.

In conclusion, the results obtained indicate that RHDV infection is a complicated biological process that modulates diverse cellular pathways. The current findings suggest that the activation of JNK is an essential component in RHDV mediated liver injury, and that there is an activation of NF- $\kappa \mathrm{B}$ and AP-1 pathways, with up-regulation of downstream targets such as VCAM-1 or COX-2. Lack of STAT3 activation, probably mediated by SOCS3 over-expression, would have contributed to the inhibition of the regenerative response. Data obtained from this animal model confirm the presence of molecular mechanisms contributing to liver damage and lack of regeneration and support its usefulness in the investigation of potential novel therapeutical modalities in FHF.

Acknowledgements. CIBERehd was funded by the Instituto de la Salud Carlos III, Spain. This work was partially supported by a grant from the Fondo de Investigación Sanitaria (PI/021121), Spain.

\section{REFERENCES}

[1] Alonso C., Oviedo J.M., Martín-Alonso J.M., Díaz E., Boga J.A., Parra F., Programmed cell death in the pathogenesis of rabbit hemorrhagic disease, Arch. Virol. (1998) 143:321-332.

[2] Arbadi S., Maier R.V., Mitogen-activated protein kinases, Crit. Care Med. (2002) 30:S74-S78.

[3] Bélanger M., Butterworth R.F., Acute liver failure: a critical appraisal of available animal models, Metab. Brain Dis. (2005) 20:409-423.
[4] Chen L.W., Chang W.J., Wang J.S., Hsu C.M., Thermal injury-induced peroxynitrite production and pulmonary inducible nitric oxide synthase expression depend on JNK/AP-1 signaling, Crit. Care Med. (2006) 34:142-150.

[5] Chen W.Y., Ho K.C., Leu J.H., Liu K.F., Wang H.C., Kou G.H., Lo C.F., WSSV infection activates STAT in shrimp, Dev. Comp. Immunol. (2008) $32: 1142-1150$

[6] Dias A.S., Porawski M., Alonso M., Marroni N., Collado P.S., González-Gallego J., Quercetin decreases oxidative stress, NF-kappaB activation and iNOS overexpression in liver of streptozotocin induced diabetic rats, J. Nutr. (2005) 135:2299-2304.

[7] Duechting A., Tschöpe C., Kaiser H., Lamkemeyer T., Tanaka N., Aberle S., et al., Human parvovirus B19 NS1 protein modulates inflammatory signaling by activation of STAT3/PIAS3 in human endothelial cells, J. Virol. (2008) 82:7942-7952.

[8] Ekstrand-Hammarström B., Osterlund C., Lilliehöök B., Bucht A., Vitamin E down-modulates mitogen-activated protein kinases, nuclear factor-kap$\mathrm{paB}$ and inflammatory responses in lung epithelial cells, Clin. Exp. Immunol. (2007) 147:359-369.

[9] Galun E., Zeira E., Pappo O., Peters M., Rose-John S., Liver regeneration induced by a designer human IL-6/sIL-6R fusion protein reverses severe hepatocellular injury, FASEB J. (2000) 14:1979-1987.

[10] Gao B., Cytokines, STATs and liver disease, Cell. Mol. Immunol. (2005) 2:92-100.

[11] García-Mediavilla M.V., Crespo I., Collado P.S., Esteller A., Sánchez-Campos S., Tuñón M.J., González-Gallego J., Anti-inflammatory effect of the flavones quercetin and kaempferol in Chang Liver cells involves inhibition of inducible nitric oxide synthase, cyclooxygenase- 2 and reactive C-protein, and down-regulation of the nuclear factor kappaB pathway, Eur. J. Pharmacol. (2007) 557:221-229.

[12] Han C., Li G., Lim K., Defrances M.C., Gandhi C.R., Wu T., Transgenic expression of cyclooxygenase-2 in hepatocytes accelerates endotoxin-induced acute liver failure, J. Immunol. (2008) 181: $8027-8035$.

[13] Ip Y.T., Davis R.J., Signal transduction by the c-Jun N-terminal kinase (JNK)-from inflammation to development, Curr. Opin. Cell Biol. (1998) 10: 205-219.

[14] Katsuma S., Mita K., Simada T., ERK- and JNKdependent signaling pathways contribute to Bombyx mori nucleopolyhedrovirus infection, J. Virol. (2007) 81:13700-13709. 
[15] Kim W.H., Hong F., Radaeva S., Jaruga B., Fan S., Gao B., STAT1 plays an essential role in LPS/Dgalactosamine-induced liver apoptosis and injury, Am. J. Physiol. Gastrointest. Liver Physiol. (2003) 285:761-768.

[16] Kolch W., Meaningful relationships: the regulation of the Ras/Raf/MEK/ERK pathway by protein interactions, Biochem. J. (2000) 351:289-305.

[17] Kretzmann N.A., Fillmann H., Mauriz J.L., Marroni C.A., Marroni N., González-Gallego J., Tuñón M.J., Effects of glutamine on pro-inflammatory gene expression and activation of nuclear factor kappa $\mathrm{B}$ and signal transducers and activators of transcription in experimental colitis, Inflamm. Bowel Dis. (2008) 14:1504-1513.

[18] Lee W.M., Acute liver failure in the United States, Semin. Liver Dis. (2003) 23:217-226.

[19] Liu S.J., Xue H.P., Pu B.Q., Quia N.H., A new viral disease in rabbits, Anim. Husb. Vet. Med. (1984) 16:253-255.

[20] Maeda S., Chang L., Li Z.W., Luo J.L., Leffert H., Karin M., IKKbeta is required for prevention of apoptosis mediated by cell-bound but not by circulating TNFalpha, Immunity (2003) 19:725-737.

[21] Martínez-Flores S., Gutiérrez-Fernández B., Sánchez-Campos S., Gonzalez-Gallego J., Tuñón M.J., Quercetin prevents nitric oxide production and nuclear factor kappa B activation in interleukin-1 $\beta$ activated rat hepatocytes, J. Nutr. (2005) 135: 1359-1365.

[22] Mauriz J.L., Matilla B., Culebras J.M., González P., González-Gallego J., Dietary glycine inhibits activation of nuclear factor kappa $\mathrm{B}$ and prevents liver injury in hemorrhagic shock in the rat, Free Radic. Biol. Med. (2001) 31:1236-1244.

[23] Meraz M.A., White J.M., Sheehan K.C., Bach C.A., Rodig S.J., Dighe A.S., et al., Targeted disruption of the Stat1 gene in mice reveals unexpected physiologic specificity in the JAK-STAT signaling pathway, Cell (1996) 84:431-442.

[24] Mikami O., Hepatic lesions in young rabbits experimentally infected with rabbit haemorrhagic disease virus, Res. Vet. Sci. (1999) 66:237-242.

[25] Moreira A., Fraga C., Alonso M., Collado P.S., Zettler C., Marroni C., et al., Quercetin prevents oxidative stress and NF-kappaB activation in gastric mucosa of portal hypertensive rats, Biochem. Pharmacol. (2004) 68:1939-1946.

[26] Muto Y., Nouir-Aria K.T., Meager A., Alexander G.J., Edlleston A.L., Williams R., Enhanced tumour necrosis factor and interleukin-1 in fulminant hepatic failure, Lancet (1988) 2:72-74.
[27] Nakama T., Hirono S., Moriuchi A., Etoposide prevents apoptosis in mouse liver with D-galactosamine/lipopolysaccharide-induced fulminant hepatic failure resulting in reduction of lethality, Hepatology (2001) 33:1441-1450.

[28] Pan H., Xie J., Ye F., Gao S.J., Modulation of Kaposis's sarcoma-associated herpesvirus infection and replication by $\mathrm{MEK} / \mathrm{ERK}$, JNK, and p38 multiple-mitogen-activated protein kinase pathways during primary infection, J. Virol. (2006) 80:5371-5382.

[29] Panteva M., Korkaya H., Jameel S., Hepatitis viruses and the MAPK pathway: is this a survival strategy?, Virus Res. (2003) 92:131-140.

[30] Pauli E.K., Schmolke M., Wolff T., Viemann D., Roth J., Bode J.G., Ludwig S., Influenza A virus inhibits type I IFN signaling via NF-kappaB-dependent induction of SOCS-3 expression, PLoS Pathog. (2008) 4:e1000196.

[31] Persico T., Savasi V., Ferrazzi E., Oneta M., Semprini A.E., Simoni G., Detection of human immunodeficiency virus-1 RNA and DNA by extractive and in situ PCR in unprocessed semen and seminal fractions isolated by semen-washing procedure, Hum. Reprod. (2006) 2:1525-1530.

[32] Pestka S., The human interferon alpha species and receptors, Biopolymers (2000) 55:254-287.

[33] Qiu Z., Kwon A.H., Tsuji K., Kamiyama Y., Okumura T., Hirao Y., Fibronectin prevents D-galactosamine/lipopolysaccharide-induced lethal hepatic failure in mice, Shock (2006) 25:80-87.

[34] Rutherford A., Chung R.T., Acute liver failure: mechanisms of hepatocyte injury and regeneration, Semin. Liver Dis. (2008) 28:167-174.

[35] Sánchez-Campos S., Álvarez M., Culebras J.M., González-Gallego J., Tuñón M.J., Pathogenic molecular mechanisms in an animal model of fulminant hepatic failure: rabbit hemorrhagic viral disease, J. Lab. Clin. Med. (2004) 144:215-222.

[36] San-Miguel B., Álvarez M., Culebras J.M., González-Gallego J., Tuñón M.J., N-acetyl-cysteine protects liver from apoptotic death in an animal model of fulminant hepatic failure, Apoptosis (2006) 11:1945-1957.

[37] Schattenberg J.M., Singh R., Wang Y., Lefkowitch J.H., Rigoli R.M., Scherer P.E., et al., JNK1 but not JNK2 promotes the development of steatohepatitis in mice, Hepatology (2006) 43:163-172.

[38] Schwabe R.F., Bradham C.A., Uehara T., Hatano E., Bennett B.L., Schoonhoven R., Brenner D.A., c-Jun-N-terminal kinase drives cyclin D1 expression and proliferation during liver regeneration, Hepatology (2003) 37:824-832. 
[39] Stravitz R.T., Critical management decisions in patients with acute liver failure, Chest (2008) 134:1092-1102.

[40] Streetz K., Leifeld L., Grundmann D., Ramakers J., Eckert J., Spengler U., et al., Tumor necrosis factor $\alpha$ in the pathogenesis of human and murine fulminant hepatic failure, Gastroenterology (2000) 119:446-460.

[41] Suzuki Y.J., Forman H.J., Sevanian A., Oxidants as stimulators of signal transduction, Free Radic. Biol. Med. (1997) 22:269-285.

[42] Takahashi K., Umehara Y., Umehara M., Nishimura A., Naruumi S., Toyoki Y., et al., Plasma exchange-based plasma recycling dialysis system as an artificial liver support, Ther. Apher. Dial. (2008) $12: 264-270$.

[43] Takamura M., Matsuda Y., Yamagiwa S., Tamura Y., Honda Y., Suzuki S., et al., An inhibitor of c-Jun NH2-terminal kinase, SP600125, protects mice from D-galactosamine/lipopolysaccharideinduced hepatic failure by modulating $\mathrm{BH}$-only proteins, Life Sci. (2007) 80:1335-1344.

[44] Taub R., Hepatoprotection via the IL-6/Stat3 pathway, J. Clin. Invest. (2003) 112:978-980.

[45] Tung W.H., Sujn C.C., Hsieh H.L., Wang S.W., Horng J.T., Yang C.M., EV71 induces VCAM-1 expression via PDGF receptor, PI3-K/Akt, p38 MAPK, JNK and NF-kappa B in vascular smooth muscle cells, Cell. Signal. (2007) 19:2127-2137.

[46] Tuñón M.J., Sánchez-Campos S., GarcíaFerreras J., Alvarez M., Jorquera F., Gonzalez-Gallego J., Rabbit hemorrhagic viral disease: characterization of a new animal model of fulminant liver failure, J. Lab. Clin. Med. (2003) 141:272-278.

[47] Tuñón M.J., Alvarez M., Culebras J.M., González-Gallego J., An overview of animal models for investigating the pathogenesis and therapeutic strategies in acute hepatic failure, World J. Gastroenterol. (2009) 15:3086-3098.

[48] Van de Kerkhove M.P., Hoekstra R., Chamuleau R.A., van Gulik T.M., Clinical application of bioartificial liver support systems, Ann. Surg. (2004) 240:216-230.

[49] Whitmarsh A.J., Davis R.J., Transcription factor AP-1 regulation by mitogen-activated protein kinase signal transduction pathways, J. Mol. Med. (1996) 74:589-607.

[50] Vlotides G., Sörensen A.S., Kopp F., Zitzmann K., Cengic N., Brand S., et al., SOCS-1 and SOCS-3 inhibit IFN-alpha-induced expression of the antiviral proteins 2,5-OAS and MxA, Biochem. Biophys. Res. Commun. (2004) 320:1007-1014.

[51] Wolf D., Hallmann R., Sass G., Sixt M., Kusters S., Fregien B., et al., TNF-alpha-induced expression of adhesion molecules in the liver is under the control of TNFR1-relevance for concanavalin A-induced hepatitis, J. Immunol. (2001) 166:1300-1307.

[52] Yamada Y., Kirillova I., Peschon J.J., Fausto N., Initiation of liver growth by tumor necrosis factor: deficient liver regeneration in mice lacking type I tumor necrosis factor receptor, Proc. Natl. Acad. Sci. USA (1997) 94:1441-1446.

[53] Yeh C., Lin P.Y., Liao M.H., Liu H.J., Lee J.W., Chiu S.J., et al., TNF- $\alpha$ mediates pseudorabies virus-induced apoptosis via activation of p38 MAPK and JNK/SAPK signaling, Virology (2008) 381: 55-66.

[54] Zhu H., Shang X., Terada N., Liu C., STAT3 induces anti-hepatitis $\mathrm{C}$ viral activity in liver cells, Biochem. Biophys. Res. Commun. (2004) 324:518-528. 